\title{
Integrated charging infrastructure: cognitive interviews to identify preferences in charging options
}

\author{
Stephan Daubitz ${ }^{1} \cdot$ Ines Kawgan-Kagan $^{1}$ (1)
}

Received: 2 January 2015 / Accepted: 22 September 2015 / Published online: 12 October 2015

(C) The Author(s) 2015. This article is published with open access at SpringerLink.com

\begin{abstract}
Purpose The aim of this paper is to provide insight into how people assess different charging options in the context of electric mobility and how charging can be integrated into daily activities. The central research question concerns the acceptance of fast charging with direct current up to $200 \mathrm{kWh}$ relative to alternative charging concepts such as inductive charging or battery changes as a part of mobility routines.

Method The Repertory Grid Technique uses cognitive interviews based on the Personal Construct Theory by George Kelly to motivate respondents to reflect electric mobility beyond the insights that regular interview forms can provide. 20 respondents from Berlin were asked about their subjective perceptions and emotions relating to electric mobility and to different charging options.

Results Charging processes are accepted when they appear to proceed subconsciously. That is, options are accepted when they are not perceived to result in trip interruptions or delays. Fuelling a vehicle with an internal combustion engine is mostly not considered as a trip interruption, and provides a
\end{abstract}

Description The special research method repertory grid gives the opportunity to get to the bottom of cognitive perceptions and emotions relating to electric mobility combining qualitative and quantitative approaches.

This article is part of the Topical Collection on Driving Societal Changes towards an Electro-mobility Future

Ines Kawgan-Kagan

ines.kawgan-kagan@tu-berlin.de

Stephan Daubitz

stephan.daubitz@tu-berlin.de

1 Institute of Land and Sea Transport, Department of Integrated Transport Planning, Technical University Berlin, Salzufer 17 - 19, 10587 Berlin, Germany benchmark to which all other charging options are compared. We identify the need to integrate charging options into existing mobility patterns, and provide evidence arguing against the need for a comprehensive charging infrastructure from a users' perspective.

Conclusions The Repertory Grid technique provides a valuable tool for the exploration of perceptions of public and private charging infrastructure. By overcoming difficulties in reaching an underlying reality that are inherent to standard interviews, this technique may be useful in creating a shift towards a more sustainable mobility.

Keywords Perception of e-mobility $\cdot$ e-mobility $\cdot$ Charging options $\cdot$ Integrated charging $\cdot \mathrm{BEV} \cdot$ Repertory grid technique $\cdot$ Qualitative interviews $\cdot$ Preferences $\cdot$ Acceptance $\cdot$ Fast charging $\cdot$ Cognitive interviews $\cdot$ Combined charging systems

\section{Introduction}

The shift towards electric mobility as a sustainable form of urban transport leads to a change of familiar traffic experiences for most people. Traffic behaviour as the implemented translocations is mostly routinized [1, 23, 43]. Mobility routines are internalized and repeatedly performed decisions and behaviour for potential translocations prior to the actual mode choice [2]. Once strategies are developed they are difficult to change, particularly by external forces [1]. Because the process of refuelling vehicles with an internal combusting engine (ICEVs) is familiar and fits within such a routine, it generally proceeds subconsciously. In contrast, the process of charging battery electric vehicles (BEVs) is unfamiliar and may consequently be seen as more effortful. 
Electric mobility, encompassing a combination of public transport and electrically operated vehicles, requires the adoption of new strategies and methods to assess, differentiate, and select sustainable travel methods. In the context of BEVs, it is important to consider the perceptions of potential users including factors such as range limitation or even range anxiety [34]. Charging of battery electric vehicles is discussed in terms of capacity and infrastructure considering distances. In order to create a shift towards a more sustainable mobility subjective perception is of crucial importance for the acceptance of charging options as coming along with the use of BEVs and therefore needs to be analysed.

Previous studies mostly discussed charging processes from a technical perspective regarding capacity, performances, energy sources and charging times [6,33]. Other studies cover cost efficiency in terms of return on investment [40] and optimization of efficiency $[14,45]$. Costs of infrastructure has been analysed and optimized concerning processes and model of planning for charging infrastructure are proposed, including interval-distance ratio, charge capacity and charging power [19, 21, 33, 44]. The impact of charging EVs on grids considering differences in energy storage technology, infrastructure, and market context for optimization of driving range by minimizing costs has been analysed [7, 29, 41]. Consumers and their mobility behaviour have been mostly researched in terms of optimization of electricity costs and ranges partially considering range anxiety [22, 29]. Fast charging was assessed by using current mobility behaviour to model optimized fast charging infrastructure [30]. Asking for day-to-day usability of BEVs, studies focussed on range and average speed using aggregated data and implying invariable mobility behaviour [20, 35].

From a psychological point of view, Lim stated in 2014 that range anxiety is one of the two major barriers to mass adoption of electrically powered vehicles besides resale anxiety [28]. Bakker even sees an elaborated fast charging infrastructure as the key factor for the acceptance of electric vehicles since pubic charging stations relief users from range anxiety [3]. Range anxiety, respectively the perception of comfortable ranges related to charging behaviour has been presumed as a given and constant factor and researched in order to optimize charging processes [10]. Although Franke states that elucidation provides a promising way of addressing perceived range anxiety [12], most studies assume persistent mobility behaviour. It is used as a given and unchangeable factor when analysing range and charging behaviour. Picking up this issue, we analyse charging options using a qualitative approach, which allows a deep reflection of users' mobility routines in order to reach an underlying truth. The analysis of perception of range so far did not take the whole process of charging into consideration. The issue of integrating charging into daily routines and mobility behaviour has not been addressed from a users' perspective. So far, psychological analyses focussed on a superficial assessment considering range and charging times as isolated factors. Cost efficiency and charging processes have been treated without the context of daily routines. Our research integrates all aspects and combines charging processes and infrastructure requirements as well as comparing several alternative options, discussing integration into the daily life of users.

This research is part of the Combined Charging System (CCS) project, including qualitative and cognitive interviews focussed on the cognitive assessment of different charging options for BEVs. CCS combines regular charging with alternating current $(\mathrm{AC})$ and fast charging with direct current (DC) in one charging station. The aspect of fast charging is of special interest, since it gives the opportunity to charge an electric vehicle with up to $200 \mathrm{kWh}$, which leads short waiting times. To address differences in perception a research approach has been chosen that aims for revealing the current state of acceptance, considering daily mobility routines. This acceptance of different charging options and refuelling is investigated for the first time with a qualitative research method named Repertory Grid Technique (RGT), which is based on the Personal Construct Theory (PCT) by George A. Kelly [25]. PCT provides an appropriate theoretical foundation in order to elicit the individual cognitive systems of subconscious assessments of items [25, 26].

\section{Personal construct theory}

Kelly argues that perception is not an objective process that can be compared easily across individuals [26]. Each individual has a specific context of assessment criteria, which leads to a subjective perception. The criteria people use to evaluate objects and subjects are not naturally given. In fact, they are constructed and therefore named constructs. Personal constructs usually consist of two poles, which provide a range of anticipation between a mostly positive pole and a negative counter pole [4]. People rate objects, subjects, situations or issues within this range of a construct [32]. Combining ratings leads to an individual perception regarding the criteria that are important to the respective individual. Some of the constructs are unstable, some constructs are more important than others, and different constructs of one individual may even be internally inconsistent. The process of assessment is usually subliminal and helps to anticipate an individual's surrounding by shaping or creating expectations and acceptance [18]. Societal and publicly distributed constructs have a significant impact on the generation and modification of constructs of individuals.

Setting constructs in a relation to one another creates an individual system of evaluation $[25,26]$. For every item, a person has his or her own and very specific set of constructs to assess. Instead of using objective categories to understand a 
person's perception, PCT sees the person as the creator of his or her individual system of assessment. It is shaped by experiences and is constantly influenced by new sources of information [38]. Consequently, the perception of an individual can never stand for an objective truth and cannot be assessed via standardised and supposed objective criteria.

Because the majority of the German population currently lacks experiences with electric mobility, constructs assessing electric mobility and charging options are mostly built through public media and comparison to vehicles with an internal combustion engine. Therefore, perceptions of charging options are heavily influenced by regular refuelling procedures, with which car drivers are usually familiar. The assessment of charging options for battery electric vehicle, for example, is determined by subjective categories that are susceptible to interpretation [42]. For two different individuals a particular wording, despite being objectively the same, can have two completely different meanings. Therefore, the individuality of construct systems requires a specific method to capture how a person perceives an item. Kelly developed the Repertory Grid Technique to grasp subjective construct systems. Even qualitative depth or semi-structured interviews have limitation when exploring subconscious routines [38]. Therefore, instead of observing characteristics and explaining people using objective observations, he asked the respondents to explain their world, as they perceive it [25].

\section{Repertory grid technique}

The analysis of subjective perception due to individual construct systems requires an interview technique that gives the respondents a possibility to anticipate items according to their perception without constraints. Kelly developed a method for understanding this subjective perceptions based on his PCT [25-27]. Since a construct system is shaped by personal experiences and cannot be observed directly, respondents must be asked to reflect on and identify the constructs they use to anticipate situations, people or other items. RGT was originally created for psychotherapeutic treatments of patients [25]. In this task, participants were asked to assess mainly people, who they categorized as belonging to specific groups such as family or friends [13]. In addition to psychotherapeutic treatment, RGT has been used in other research fields, as well for marketing reasons. To date, RGT has not been used in many studies covering mobility research: in the field of tourism research, it has been repeatedly used to gain insight into individuals" perception of destinations [9, 36, 37]. Another study by Dick examined the application of RGT for everyday traffic behaviour for individuals. However, although it focused on the method and on ways of analysing the data, it unfortunately did not contain an analysis of the topic itself [8]. Consequently, our study was designed to fill this gap in the literature by examining perceptions of charging options as an aspect of electric mobility using the Repertory Grid Technique.

We conducted 20 computer-assisted personal interviews (CAPI) in November and December 2013 supported by special software for the Repertory Grid Technique called GridSuite [17]. Respondents with a higher affinity towards cars were recruited through various ways: Potential respondents were addressed either directly, online via a portal for professional networking or through a chain-referral sampling technique. Higher affinity towards cars was defined as either using one's own car on a daily basis or viewing it as a hobby. All of the participants had some experience with BEVs: Ten respondents reported having actual driving experience; of these, one woman reported driving her BEV to work every day. Another man reported driving an electric company car within Berlin. The rest reported having at least seen BEVs in their everyday life. All of the participants were either self-employed or employed at the point of the interview, and eight of them were female.

The elements were presented to the respondents in triads of cards [16]. We asked them to group two cards together according to a shared attribute. After an initial intuitive grouping, they were asked to reflect on which aspects of the items may have led them to assign their groupings. The attribute of the two similar elements represents the (positive) construct pole. In order to elicit the counter pole, the respondents had to name what distinguishes those two from the third element as given in Fig. 1. Respondents largely did not have issues phrasing the first constructs during a session. After a few triads it became harder to put the intuitive grouping into concrete words. Whenever constructs meanings started to become repetitive, and respondents were unable to generate new constructs, this part of the interview stopped. Using this strategy, each respondent elaborated 7 to 8 constructs for a grid for a total of 156 constructs describing charging options and refuelling. The interviews were conducted in German.

Since the focus of the present research is the acceptance of different charging options of BEVs, we used seven charging options. In addition, we used the refuelling of ICEVs as a process that was well-known to our interviewees. Table 1 contains the elements as they were presented in German to the respondents during the interview. Defining the elements for a repertory grid has been previously argued to be the most difficult aspect of designing the interview [18]. To address this issue, we identified our elements in a pilot study that included ten semi-structured qualitative interviews conducted in the summer of 2013. The results of these qualitative interviews were then used to generate the narratives and pictures used to present the elements.

After eliciting the construct poles, we asked the respondents to rate all the elements on a scale from one to five for each construct, where one stands for the construct pole and five for the counter pole [24]. In addition to collecting the 


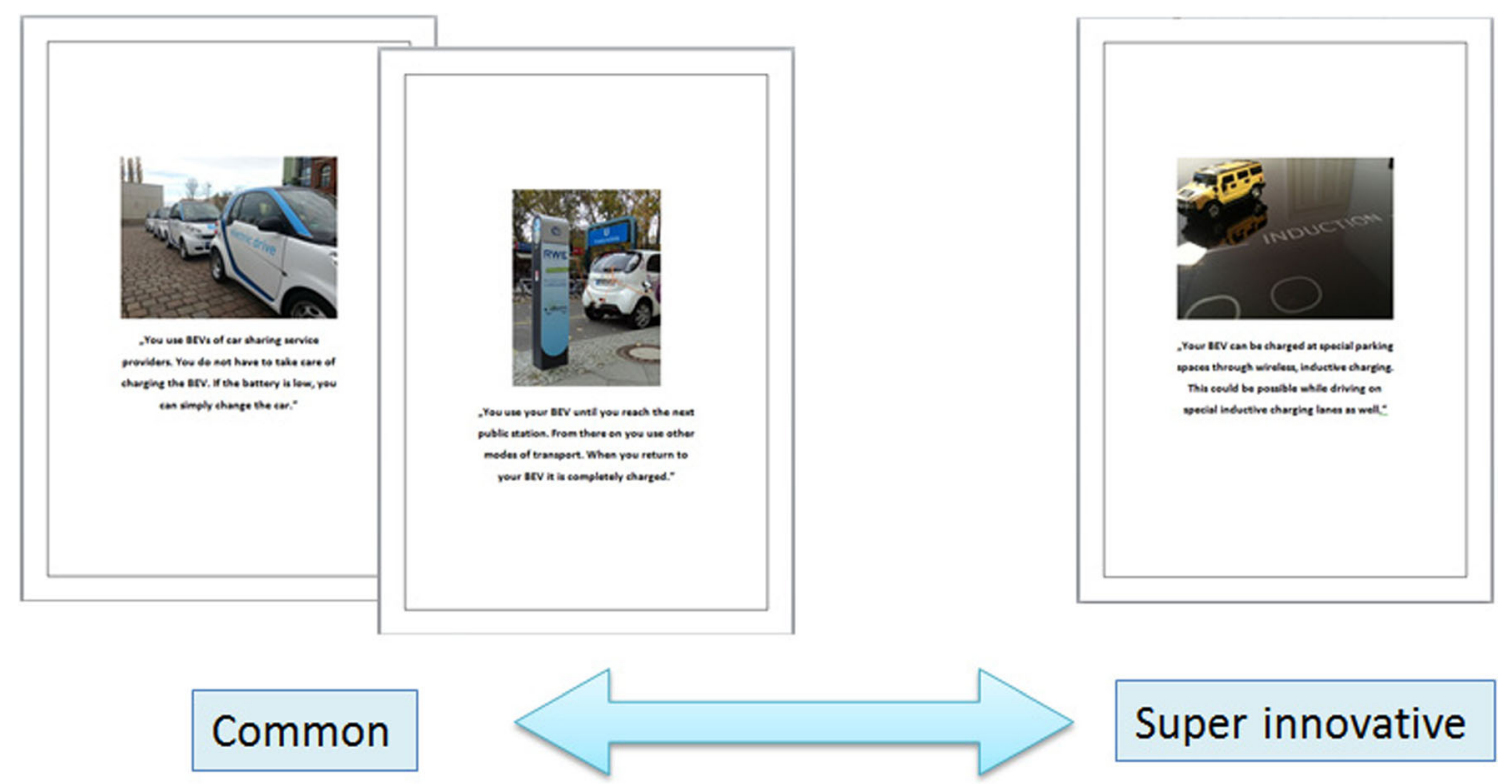

Fig. 1 Example of Triad (for more details see Table 1)

constructs and ratings, the interviews were recorded in order to reproduce the meanings of the specific words that were used to describe the differences. The meanings of particular wordings can exhibit substantial differences from one respondent to another [42]. Consequently, to understand the subjective meanings of different construct wordings, it is important to consider how a construct was generated during an interview.

At the end of the interview, we generated a complete grid for each interviewee on the basis of their responses. Each grid contained the elements of a particular topic, a construct pole, and a respective counter pole as well as the ratings of all elements regarding all constructs [4]. The set of generated constructs shows which aspects of a particular topic play a role in its perception. The following Table 2 shows the examplary connection of topic, constructs, elements and ratings for a particular respondent in form of a complete grid:

The RGT combines qualitative narrative and quantitative aggregated material [31]. The first step of analysis was to perform a content analysis of the qualitative audio material corresponding to the constructs, to gain a better understanding of their actual meaning [42]. Additionally, the ratings were analysed for internal consistency, because occasionally the meaning of a construct changed over the course of the interview. A complete grid displays the respective attitudes and values of an individual. Since construct systems of individuals are unique, it is not possible to directly compare the results of the ratings of the elements between respondents $[25,39]$. That said, aggregating constructs and ratings can be a useful avenue to gain insight into the perception of specific issues [24, 31]. Thus, the constructs were used to generate a collective construct system that captures the scope of perceptions of charging options [38]. These constructs were then further analysed to explore our special interest in fast charging. The aggregated constructs lead to specific dimensions having a significant impact on the assessment of charging and refuelling options.

The next analysis step consisted of summarizing each respondent's ratings of the elements to explore similarities and differences in how they perceived the elements. Ratings from construct systems cannot be compared across the entire sample, because they represent different assessment dimensions $[18,25]$. Nevertheless, the elements and ratings can be compared to each other within the context of each individual respondent's construct system. This comparison yields each respondent's individual acceptance of an option based on the constructs elicited during the interview, taking into context the results of the content analysis. This method results in the identification of shared characteristics that play a crucial role for the perception and acceptance of fast charging. For each element, we listed the respective elicited construct poles, which were either rated with one or five.

Setting all ratings in a relation to the number of elements and constructs, it is possible to calculate the percentage of element similarity for each respondent according to his or her construct system [15]. As described in the previous section, we focussed on comparing fast charging to the rest of the elements. See Table 11 in the results section for a visualisation of these data. An advantage of this analysis method is that the correlations between assessment criteria reveal acceptance beyond what respondents said during the interview.

\section{Results}

To identify assessment criteria and acceptance for different charging options, we present the range of relevant constructs 
Table 1 Elements as presented in the Interview (translated from German into English)

\begin{tabular}{|c|c|c|}
\hline Element & Story as presented in the interview & Picture \\
\hline Refuelling & $\begin{array}{l}\text { You use your car with an internal-combustion engine the } \\
\text { common way and refuel it the way you are used to. }\end{array}$ & \\
\hline $\begin{array}{l}\text { Normal } \\
\text { charging } \\
\text { (public) }\end{array}$ & $\begin{array}{l}\text { You can charge your BEV in public space at a special } \\
\text { charging station. You go to work and take your } \\
\text { recharged BEV to go home after work. }\end{array}$ & \\
\hline $\begin{array}{l}\text { Normal } \\
\text { charging } \\
\text { (home) }\end{array}$ & $\begin{array}{l}\text { You can charge your BEV at a reserved parking space } \\
\text { next to your home. Usually this is the origin and } \\
\text { destination of your trips. }\end{array}$ & \\
\hline $\begin{array}{l}\text { Inductive } \\
\text { charging }\end{array}$ & $\begin{array}{l}\text { Your BEV can be charged at special parking spaces } \\
\text { through wireless, inductive charging. This could be } \\
\text { possible while driving on special inductive charging } \\
\text { lanes as well. }\end{array}$ & \\
\hline Fast charging & $\begin{array}{l}\text { You drive with your BEV to the next fast charging station } \\
\text { at the gas station and recharge your car up to } 80 \% \\
\text { within } 30 \text { minutes. Afterwards you can continue your trip. }\end{array}$ & \\
\hline $\begin{array}{l}\text { Battery } \\
\text { replacement }\end{array}$ & $\begin{array}{l}\text { You can charge your BEV at a changing station, where } \\
\text { your battery is being exchanged within five minutes. }\end{array}$ & \\
\hline Car sharing & $\begin{array}{l}\text { You use BEVs of car sharing service providers. You do } \\
\text { not have to take care of charging the BEV. If the battery } \\
\text { is low, you can simply change the car. }\end{array}$ & \\
\hline Intermodality & $\begin{array}{l}\text { You use your BEV until you reach the next public } \\
\text { station. From there on you use other modes of transport. } \\
\text { When you return to your BEV it is completely charged. }\end{array}$ & \\
\hline
\end{tabular}

for all charging option and refuelling. In addition, special emphasis is placed on analysis of perceptions of fast charging of BEVs. As a first step, we will provide an overview of the assessments of all the different charging and refuelling options. Subsequently, we will report analyses designed to compare fast charging with other charging and refuelling options to gain a better understanding of the fast charging assessment criteria.

\subsection{Assessment of charging and refuelling options}

All respondents approached charging options by comparing them to their known and mostly routinized traffic behaviour. Familiar car ranges and refuelling at a gas station both seemed to be a first reference point in driving preferences. Experiences with electric mobility also played a crucial role in the acceptance of different charging options, in line with findings from 
Table 2 Grid example, topic: charging and refuelling options

\begin{tabular}{llllllllll}
\hline & \multicolumn{1}{l}{$\begin{array}{l}\text { Elements } \\
\text { Construct pole }\end{array}$} & \multicolumn{1}{l}{$\begin{array}{l}\text { Battery } \\
\text { exchange }\end{array}$} & $\begin{array}{l}\text { Inductive } \\
\text { charging }\end{array}$ & $\begin{array}{l}\text { Regular } \\
\text { refuelling }\end{array}$ & $\begin{array}{l}\text { Fast } \\
\text { charging }\end{array}$ & $\begin{array}{l}\text { Car } \\
\text { sharing }\end{array}$ & $\begin{array}{l}\text { Inter- } \\
\text { modality }\end{array}$ & $\begin{array}{l}\text { Regular } \\
\text { charging }\end{array}$ & $\begin{array}{l}\text { Home } \\
\text { charging }\end{array}$ \\
\hline Common & 5 & 2 & 5 & 2 & 1 & 2 & 4 & 3 & Counter pole \\
Hard to realise & 1 & 5 & 1 & 2 & 5 & 5 & 2 & 3 & Super innovative \\
Ecol. aware & 2 & 1 & 1 & 1 & 5 & 1 & 1 & Realisable \\
Forced & 1 & 4 & 5 & 3 & 4 & 3 & 3 & 5 & Not ecol. aware \\
Difficult & 1 & 5 & 1 & 3 & 5 & 3 & 3 & 5 & Not forced \\
Cost-intense & 1 & 4 & 1 & 4 & 1 & 4 & 4 & 4 & Simple \\
Inconvenient & 1 & 4 & 4 & 2 & 4 & 4 & 4 & 5 & Cost-efficient \\
\hline
\end{tabular}

previous studies $[5,11]$. Normative backgrounds were less relevant. Nevertheless, during the interviews important assessment criteria beyond range or even range anxiety were elicited.

\subsubsection{Refuelling}

The actual trip interruption caused by refuelling an ICEV is not recognized by most of the respondents. It is a subconscious part of traffic behaviour and its duration seems to be an accepted loss of time. Initially, it served as a benchmark for acceptance of charging for the majority of the sample, and was connected to the constructs "independency", "flexibility" and "availability". The number of constructs regarding refuelling elicited during the interviews was the highest for all the presented options (see Table 3). Compared to other elements, it was perceived as very "fast" and "flexible" and was associated with greater perceived mobility. It is "always available" and does not constrain the respondents in any way. They felt able to go where and when they want without having to plan anything. However, there were also drawbacks associated with refuelling ICEVs: compared to the other elements, respondents perceived it to be "dirty", "out of fashion", or even "obsolete". Despite these drawbacks, respondents largely accepted it as an option that is suitable to everyone's life and mobility requirements.

\subsubsection{Normal charging (public)}

The scope of perceptions of charging in public in specifically reserved parking spaces was substantially smaller than of the other options (see Table 4). It was mostly perceived as being "slow" and "uncomfortable", and to require respondents "to

Table 3 List of constructs regarding refuelling, $N=20$, Berlin

\begin{tabular}{|c|c|c|c|}
\hline Realizable $(10 \times)$ & (I am) free & Fully developed & Not time-consuming \\
\hline Fast $(8 \times)$ & Acceptable & Given infrastructure & Obsolete \\
\hline Flexible (in time) $(8 \times)$ & According to travel behaviour & Having sole responsibility & Out of fashion \\
\hline Unconstrained (use) $(4 \times)$ & Conventional & I am not going to lose anything & Past \\
\hline (It is) mine $(3 \times)$ & Cost intense & I have to do something & Permanent Mobility \\
\hline Comfortable $(3 \times)$ & Does not constrain my individuality & I know what I've got & Private \\
\hline Harmful to the environment $(3 \times)$ & Does not interrupt my mobility & Individual & Provides mobility \\
\hline Independent $(3 \times)$ & Don't have to plan my time & Keeps the possibility of being spontaneous & Public \\
\hline Always available $(2 \times)$ & Don't have to take care & Known & Regular speed \\
\hline Common $(2 \times)$ & Don't have to wait & Long range & Reliable \\
\hline Dirty $(2 \times)$ & Efficient & Low start-up costs & Safe offer \\
\hline Don't have to change routines $(2 \times)$ & Everything is possible & Many possible ways to use & Societal acceptance \\
\hline Easy $(2 \times)$ & Exclusive & My living room & To take care \\
\hline Everyday-life like $(2 \times)$ & Expensive & My mobility stays as it is & Uniform transport \\
\hline Free $(2 \times)$ & External resources & Need to take care & Use as it is \\
\hline Not constrained to a location $(2 \times)$ & Fits my daily life & Not bound to supplier of electric energy & Works for everybody \\
\hline Practical $(2 \times)$ & Flexible in time & Not innovative & \\
\hline Safe (technology) $(2 \times)$ & For long term use & Not susceptible to vandalism & \\
\hline
\end{tabular}


change routines", because it restricts individuals to remaining in specific locations. Respondents did not yet trust in the existing infrastructure. Consequently, this option was associated with uncertainty. Most of the respondents excluded this charging option as a possibility for themselves because they reported not having seen any charging stations along their route to or from work. Nevertheless, it is the most "known" charging option to the interviewees, although it did not result in many construct poles. Even after reflecting their traffic behaviour routines, the majority of respondents did not see this option as acceptable. Most of the respondents were concerned about the possibility of failing to locate charging station, or if they were to find a charging station it might be occupied. Although many of the respondents initially talked about a comprehensive charging infrastructure, it became a less important aspect after consideration of daily routines.

\subsubsection{Normal charging (home)}

The option of charging at home overnight was another highly accepted recharging method for most of the respondents (see Table 5). It was perceived as being "comfortable", and respondents reported feeling as they "don't have to take care of anything". Although the interviewees perceived it to be the slowest option, the long charging duration was partially not perceived as being stressful. The time-consumption and location-constraints were evaluated ambivalently. Because home is the origin and destination of most of the trips, respondents saw it as a "natural station" because they would have to "go there anyway", as phrased by one respondent. Charging at this "natural station" was seen as something that would naturally "happen along the way", and was consequently not perceived as an interruption or as a loss of time. One respondent phrased a picturesque contrast of "my living room" for charging at home versus "to be visiting" for car sharing services. She associates the construct pole "my living room" with a very positive, warm, and cosy feeling, as well as with safety and privacy.

\subsubsection{Inductive charging}

The perception and assessment of inductive charging as an easy option of charging a BEV was mostly positive (see Table 6). It was seen as a very fast option, which does not necessitate exerting much additional effort, or having to change routines. It does not appear to require additional planning or unusual actions. Rather, it "happens along the way", as phrased by one respondent. Other positive construct poles that were used to evaluate inductive charging were responses such as "sorcery" or "all-round carefree package". This charging option does not appear lead to behavioural changes for respondents, and even makes refuelling stops redundant. Nevertheless, although the reception of inductive charging was largely positive, there were also some negative perceptions associated with this option. In the presented form, inductive charging presents an unsafe solution. Unsolved technical issues are associated with massive impacts on health and the environment (e.g., electromagnetic radiation). Consequently, a lot of "public resistance" is expected. Additionally, the high costs associated with the implementation of this technology also played a crucial role in its acceptance. Despite these concerns regarding safety and cost, inductive charging was the most accepted form of charging across our sample as it is perceived as almost invisible and very "comfortable".

\subsubsection{Fast charging}

For the assessment of fast charging, the factor of duration presents an important consideration (see Table 7). Half an hour of charging results in the inescapable consequence of having to change the traffic behaviour routines. Respondents were aware of this necessity, and produced both positive and negative appraisals in response. One of the respondents was unable to imagine using a fast charging station, because it would force him to "rearrange" his entire work day. This respondent was unable to think of potential ways to use the half hour required for charging in a productive manner. He was not willing to bring a laptop, documents, or other required

Table 4 List of constructs regarding normal charging in public, $N=20$, Berlin

\begin{tabular}{lll}
\hline Slow $(7 \times)$ & Public $(2 \times)$ & Getting nowhere \\
Realizable $(4 \times)$ & Already existing & Having sole responsibility \\
Known (Conventional) & Bound to supplier of electric energy & I am not going to lose anything \\
Safe (technology) $(3 \times)$ & Calms me down & Individual \\
Uncomfortable $(3 \times)$ & Comfortable & It is mine \\
Environment friendly $(2 \times)$ & Constrains my individuality & Many possible ways to use \\
Have to change routines $(2 \times)$ & Dependent & My living room \\
Need to take care $(2 \times)$ & External resources & My vehicle \\
Not flexible $($ in time $(2 \times)$ & Flexible (time) & Need to plan my time \\
Not practical $(2 \times)$ & For long term use & Need to stay home \\
\hline
\end{tabular}


Table 5 List of constructs regarding charging at home, $N=20$, Berlin

\begin{tabular}{|c|c|c|c|}
\hline Comfortable $(7 \times)$ & Relaxed in time $(2 \times)$ & For long term use & Not forced \\
\hline Don't have to take care of anything $(5 \times)$ & Time-consuming $(2 \times)$ & Free & Not innovative \\
\hline Slow $(5 \times)$ & Unconstrained use $(2 \times)$ & Happens along the way & Not susceptible to vandalism \\
\hline (It is) mine $(4 \times)$ & According to travel behaviour & Have to change routines & Not time-consuming \\
\hline Constrained (to a location) $(4 \times)$ & Calms me down & Having sole responsibility & One Possibility of use \\
\hline Not flexible $(4 \times)$ & Cannot use other modes & I am not going to lose anything & Permanent Mobility \\
\hline Realizable $(4 \times)$ & Constrains my individuality & I know what I've got & Private resources \\
\hline Safe (technology) $(4 \times)$ & Dependent & Individual & Purely electric \\
\hline I have to do something $(2 \times)$ & Does not interrupt my mobility & Low cost & Relaxed \\
\hline Known $(2 \times)$ & Easy & Low range & Reliable \\
\hline Modern $(2 \times)$ & Efficient & Mobilizes me & Societal acceptance \\
\hline Need to plan my time $(2 \times)$ & Environment friendly & My living room & Suitable for rural areas \\
\hline Practical $(3 \times)$ & Everything is possible & Need to stay home & Uniform transport \\
\hline Private $(2 \times)$ & Exclusive & Need to wait & \\
\hline Real $(2 \times)$ & Flexible in time & Not bound to supplier of electric energy & \\
\hline
\end{tabular}

items with him in the car to use this time to work. Although most of the interviewees did not accept the duration of charging associated with fast charging, the demand of a form of mobility that is always available led respondents to name the construct "flexibility" in response to this option. Despite the positive appraisal of the flexibility of this option, the drawbacks related to the duration of charging dominated the perceptions of this option. Respondents associated fast charging with massive changes in their daily routines, and consequently named negative construct poles such as "dependency" or "not free". Other respondents with similar perceptions additionally associated fast charging with "not being practical" and with being "circumstantial". The notion of availability was a crucial element for this group of respondents in their assessment of charging and refuelling options. To them, mobility seems to be requiring constant access and a lack of interruptions in use. Anything that differs from this conception of mobility appears to be an "obstacle" or "interference".

\subsubsection{Battery replacement}

Charging options that were perceived as being similar to normal refuelling appeared to be more acceptable to the respondents relative to other options (see Table 8 ). In this study, battery replacement at a gas station was seen as a familiar process as it is associated with similar durations and locations to which individuals are already accustomed. This option was mostly perceived as a "fast", "flexible", "modern" and "comfortable"

Table 6 List of constructs regarding inductive charging, $N=20$, Berlin

\begin{tabular}{|c|c|c|c|}
\hline Fast $(6 \times)$ & Aesthetically acceptable & I don't know what I've got & Public resistance \\
\hline Comfortable $(5 \times)$ & All-round carefree package & I have to do something & Purely electric \\
\hline Hard to realize $(5 \times)$ & Calms me down & Independent & Quick access \\
\hline $\begin{array}{l}\text { Don't have to take care of anything } \\
(4 \times)\end{array}$ & Decent & Individual & Realizable \\
\hline Cost intense (high start-up costs) $(3 \times)$ & Difficult & Interrupted mobility & Regular speed \\
\hline Flexible $(3 \times)$ & Don't have to wait & It is mine & Relaxed (time) \\
\hline Innovative (modern) $(3 \times)$ & Don't need to do anything & Many possible ways to use & Safe \\
\hline Constrained (to a location) $(2 \times)$ & Dubious & My living room & Safe offer \\
\hline Fits my daily life $(2 \times)$ & Environment friendly & My mobility stays as it is & Sorcery \\
\hline Flexible in time $(2 \times)$ & Everyday-life like & My vehicle & Strange \\
\hline Happens along the way $(2 \times)$ & Exclusive & No need to plan my time & Suitable for long distances of daily life \\
\hline Not constrained to a location $(2 \times)$ & For long term use & Not bound to supplier of electric energy & Suitable for urban areas \\
\hline Not safe $(2 \times)$ & Future & Not clear & Thrilling \\
\hline Practical $(2 \times)$ & Given infrastructure & Not complicated & Unforced \\
\hline (I am) free & Hand over responsibility & Not susceptible to vandalism & Uniform transport \\
\hline According to travel behaviour & I am not going to lose anything & Public & Unknown \\
\hline
\end{tabular}


Table 7 List of constructs regarding fast charging in public, $N=20$, Berlin

\begin{tabular}{llll}
\hline Environment friendly $(3 \times)$ & Calms me down & I am not going to lose anything & Not constrained to a location \\
Need to take care $(3 \times)$ & Constrained to a location & I need to plan my time & Not free \\
Public $(2 \times)$ & Dependent & Individual & Not practical \\
Realizable $(2 \times)$ & Does not work for everybody & Interrupts my mobility & Obstructive \\
Safe (technology) $(2 \times)$ & Expensive & It is mine & Purely electric \\
Uncomfortable $(2 \times)$ & External resources & Known & Societal acceptance \\
Having sole responsibility & Fast & Modern & Static \\
Aesthetically Inacceptable & Flexible (time) & My living room & Unacceptable \\
All-round carefree package & Given infrastructure & My vehicle & Uniform transport \\
Bound to supplier of electric energy & Have to change routines & Not clear & \\
\hline
\end{tabular}

way to charge a BEV. It was considered to be the fastest charging method, and therefore, an adequate alternative to refuelling. Respondents were generally unwilling to change their traffic behaviour routines. For them, it was important to maintain "the possibility of being spontaneous" that is an advantage of using an ICEV, as some stated. With this option, respondents felt as though they would be free to go wherever they want without having to plan for contingencies in case the battery runs low. Despite these benefits, some disadvantages were also associated with a battery exchange: although rated as "environmental friendly" by one participant, another respondent perceived it as a waste of resources - especially of lithium. Construct poles like "hard to realize" were associated with this option, reflecting the fact that this option would likely be challenging to implement. Some respondents criticised battery replacement as an approach that leads to indispensable deposit systems. One respondent even considered himself to be exposed to higher costs, because he expected an extra charge for the service of exchanging the battery. For this respondent, the higher expenses associated with this option would be unacceptable.

\subsubsection{Car sharing}

The car sharing element was perceived both positively and negatively across the sample (see Table 9). For this option, prior experiences, particularly with free floating car sharing services played a major role in perception. Free floating car sharing presents a flexible contrast to round-trip car sharing: cars can simply be picked up on the street and do not have to be returned to a fixed station. Respondents who reported using car sharing services assessed this option through the construct "realizable", and associated it with requiring "little efforts". This form of mobility gave respondents a feeling of independence. However, respondents who reported either not having yet used these services or having used them only one or two times evaluated car sharing very differently: to these participants, availability did not seem to be guaranteed. One perceived obstacle was the required time to find a car. Relative to the charging options involving fixed stations, this option was perceived as insecure. For some respondents, owning a car was an important aspect of mobility culture and led to

Table 8 List of constructs regarding battery replacement, $N=20$, Berlin

\begin{tabular}{|c|c|c|c|}
\hline Fast $(8 \times)$ & Bound to supplier of electric energy & Given infrastructure & Not relaxed (time) \\
\hline Hard to realize $(5 \times)$ & Constrained & Happens along the way & Not susceptible to vandalism \\
\hline Comfortable $(4 \times)$ & Cost intense & I am not going to lose anything & Possibility of distant destinations \\
\hline Flexible $(4 \times)$ & Dependent & I have to do something & Public \\
\hline Unconstrained use $(4 \times)$ & Difficult & Forced & Purely electric \\
\hline$(\mathrm{I}$ am) free $(2 \times)$ & Diligent & I know what I've got & Regular speed \\
\hline Always available $(2 \times)$ & Does not constrain my individuality & Individual & Represents prejudice \\
\hline Efficient $(2 \times)$ & Does not interrupt my mobility & It is mine & Restructures my life \\
\hline Modern $(2 \times)$ & Don't have to take care of anything & Keeps the possibility of being spontaneous & Safe offer \\
\hline Need to take care $(2 \times)$ & Don't have to wait & Makes me mobile & Societal acceptance \\
\hline No need to plan my time $(2 \times)$ & Don't need to do anything & Many possible ways to use & Suitable for rural areas \\
\hline Practical $(2 \times)$ & Easy & Masculine & Super innovative \\
\hline Realizable $(2 \times)$ & Environment friendly & My living room & Uncomfortable \\
\hline Safe $(2 \times)$ & External resources & My mobility stays as it is & Uniform transport \\
\hline According to travel behaviour & Fits my daily life & My vehicle & Works for everybody \\
\hline Boring & For long term use & Not practical & \\
\hline
\end{tabular}


Table 9 List of constructs regarding car sharing, $N=20$, Berlin

\begin{tabular}{llll}
\hline Realizable $(8 \times)$ & Does not interrupt my mobility & Intermodal & Safe technology \\
Don't have to take care of anything $(3 \times)$ & Easy & Interrupts my mobility & Slow \\
Flexible $(3 \times)$ & Exchangeable & Joint & Societal acceptance \\
Comfortable $(2 \times)$ & Expensive & Known & Suitable for urban areas \\
Environment friendly $(2 \times)$ & Fast & Lazy & Time-consuming \\
External resources $(2 \times)$ & Given infrastructure & Modern & To be visiting \\
Need to take care $(2 \times)$ & Hand over responsibility & Not constrained to a location & Unconstrained use \\
Strange $(2 \times)$ & Have to change routines & Not flexible in time & Uniform transport \\
Uncomfortable $(2 \times)$ & I know what I've got & Not susceptible to vandalism & Works for everybody \\
Bound to supplier of electric energy & Independent & Provides mobility & Public \\
Clean & Ineffective & Purely electric & \\
Cumbersomely & Innovative & & \\
\hline
\end{tabular}

constructs such as "private - foreign". For these respondents, this played a major role in the evaluation of car sharing. One respondent even directly stated that he prefers it "if something is owned by him".

\subsubsection{Intermodality}

The intermodal approach that consists of using a car until reaching the next public transport station to switch to the local public traffic system did not represent a positively rated charging option (see Table 10). Predominantly, the respondents who travel monomodal by car were consequently unable to imagine travelling with such inconvenient interruptions. One of the respondents mentioned that she would feel "like losing something" (e.g., "grocery bags", "children"). Changes in travel mode were associated with the potential to lose items, which requires individuals to be careful and attentive. Most of the negative ratings of this option stem from the perception that charging at the station represents an unacceptable interruption of mobility. Thus, although this option was commonly associated with the positive perception of being "safe" and "environmental friendly", for most of the respondents it was incompatible with established daily routines. This "hybrid" is partially associated with being for commuters from the suburbs.

In the present study, the inclusion of assessments of a variety of charging and refuelling options resulted in more fine grained information about the factors that influence perceptions of mobility. A crucial factor in the constructs elicited by the respondents is prior experience with electric mobility. For current users of BEVs, the constructs relating to the need to plan both time and trips accordingly are distinct and nonnegative relative to those of respondents without experience with BEVs. One user reported that although she has to plan charging at home or at a charging station, it does not constitute an issue for her. She compared the process of adapting to the use of BEVs to the process of "adapting new routines to a new period of life, where you have to learn new patterns as well". This respondent reported that she usually charges her BEV at home, and described it as a modern and comfortable charging method. She further reported that she found it "cool not having to go to a gas station anymore".

In general, for respondent without experience driving electric vehicles or for those who do not have much information, charging options have to be close to their current routines to be seen as acceptable. Battery exchange as a substitute for refuelling seems to offer these respondents the flexibility to keep their mobility routines because this option is similar to their current mobility routines. Respondent with more experiences, however, are more open to adapting to electric mobility and are at least able to imagine integrating charging processes into their daily routines.

Although the prospect of waiting $30 \mathrm{~min}$ at a gas station was seen as unacceptable, some respondents were open to the possibility of fast charging periods if they were to be

Table 10 List of constructs regarding intermodality, $N=20$, Berlin

\begin{tabular}{|c|c|c|c|}
\hline Safe (technology) $(3 \times)$ & Comfortable & Having sole responsibility & Not flexible \\
\hline Slow $(3 \times)$ & Cumbersomely & Hybrid & Possibility of using other modes \\
\hline Environment friendly $(2 \times)$ & Don't have to change routines & Interrupts my mobility & Public \\
\hline Need to take care $(2 \times)$ & Exchangeable & Known & Relaxed in time \\
\hline Realizable $(2 \times)$ & Flexible in time & Modern & Societal acceptance \\
\hline (It is) mine & For long term use & Need to stay home & Suitable for urban areas \\
\hline Calms me down & Getting nowhere & Need to wait & Uncomfortable \\
\hline
\end{tabular}


integrated with other activities such as shopping at a mall. An alternative approach of integrated charging that was also accepted was while being at home or at work with a reliable parking space.

\subsection{Similarity in perception of fast charging and other charging and refuelling options}

The second step of analyses involves comparing the similarity values across the sample. Since the present research focusses on fast charging facilities and the requirements of such a system, in this stage fast charging was compared to the rest of the charging and refuelling options. In the foreground the relative similarity or differences in the perception of the various options was explored. Note that similarity values are distinct from acceptance. It is possible, for example, for respondents to exhibit high similarity values for both fast and regular charging, while not accepting either charging option. Thus, in addition to exploring the acceptance of these options, we used the results of the content analysis to infer some of the major differences and similarities in perception of charging and refuelling options from a users' perspective.

Table 11 shows the similarity values for fast charging compared to the other charging and refuelling options. Values are underlayed according to their height, such that lighter colours denote greater similarity and darker values denote lower similarity. Each column represents one respondent. The order of the elements in the left column is based on the overall average similarity given in the second column.

Consideration of the similarities between fast charging and regular charging in public spaces reveals that there are few differences between the two elements for the respondents. The average similarity is $82 \%$. Predominantly, respondents are not aware of differences because some of them lack the relevant experiences. Thus, their construct systems have not been modified by practical experiences and are instead based on known refuelling processes, in addition to being affected by mostly negative public constructs that have been distributed by the media. An initial scepticism is present in the perceptions of fast charging and regular charging, which stands in contrast to the well-known refuelling processes at gas stations. As a result, for most respondents a comprehensive public charging infrastructure is an initial requirement for acceptance. After taking the daily routines into account, it becomes apparent that it is not the mere amount of charging stations that results in negative perceptions. Even with fast charging, which reduces the waiting time during charging from several hours to $30 \mathrm{~min}$, was not associated with a high rate of acceptance. Respondents did not see this 30 min waiting period as something that would be practical to integrate into their individual mobility routines: First, for most of the respondents, this time was perceived as wasted because they would be unable to use this time in a productive manner (e.g., to work). The acceptance of this option was lowest for public regular (AC) and fast (DC) charging stations located in areas where users could not do anything else. Most of the respondents were not willing to change their routines to adapt to waiting times. Nevertheless, this option was accepted by respondents who were able to think of a productive way to occupy their time close to the public charging station. Possible activities included things such as short shopping for fast charging, or working for regular charging periods. Second, another perceived obstacle to this option involved concerns about a fully charged BEV: specifically, participants were concerned about the possibility of blocking a charging station with a fully charged BEV, which would inconvenience others. For some respondents, the possibility of coming home in the evening and charging the car at a public fast charging station was associated with expectations of guilt at preventing someone else in need from using the charging station. However, respondents did not seem to think it would be practical to plan to relocate the car to avoid a guilty conscience.

Charging processes currently seem to require a similar process to refuelling. Most of the respondents were initially not able to think of scenarios to integrate fast charging or regular charging in their daily traffic behaviour. Therefore, both options were mainly perceived as unacceptable in terms of practicality and convenience. Additionally, other constructs have been phrased that stand for a negative perception of fast charging compared to regular charging options: fast charging was

Table 11 Similarities of fast charging compared to other options in $\%, N=20$, Berlin

\begin{tabular}{|c|c|c|c|c|c|c|c|c|c|c|c|c|c|c|c|c|c|c|c|c|c|}
\hline Elements & $\varnothing$ & \multicolumn{20}{|c|}{ Respondents } \\
\hline Regular charging & 82 & 82 & 88 & 72 & 75 & 78 & 88 & 75 & 84 & 75 & 91 & 86 & 66 & 88 & 91 & 84 & 79 & 91 & 89 & 100 & 59 \\
\hline Intermodality & 78 & 86 & 88 & 75 & 84 & 94 & 84 & 69 & 69 & 72 & 81 & 93 & 75 & 44 & 69 & 84 & 75 & 72 & 89 & 94 & 56 \\
\hline Car sharing & 68 & 71 & 66 & 75 & 81 & 66 & 78 & 69 & 69 & 78 & 69 & 71 & 78 & 62 & 84 & 53 & 68 & 56 & 82 & 62 & 12 \\
\hline Home charging & 60 & 75 & 78 & 56 & 47 & 53 & 53 & 53 & 72 & 66 & 81 & 50 & 59 & 62 & 69 & 34 & 36 & 41 & 79 & 78 & 56 \\
\hline Inductive charging & 59 & 68 & 66 & 59 & 47 & 56 & 69 & 59 & 47 & 44 & 44 & 50 & 38 & 53 & 59 & 78 & 54 & 84 & 96 & 94 & 19 \\
\hline Battery exchange & 58 & 54 & 56 & 62 & 59 & 53 & 53 & 84 & 72 & 78 & 62 & 79 & 66 & 59 & 38 & 47 & 46 & 78 & 34 & 56 & 25 \\
\hline Refuelling & 54 & 43 & 44 & 69 & 59 & 59 & 50 & 78 & 66 & 62 & 72 & 61 & 38 & 56 & 66 & 22 & 32 & 66 & 57 & 75 & 6 \\
\hline
\end{tabular}


rated as being "more expensive". To implement fast charging, it will be necessary to build an infrastructure that must be financed by both users and taxpayers. Consequently, fast charging is perceived to have a negative societal impact. Moreover, in additional to being perceived as being very expensive, fast charging is expected to lead to higher abrasion of batteries, which also increases the costs incurred by fast charging processes. In contrast, charging at home appears to be the most cost-efficient way of charging and therefore showed the highest acceptance.

Generally, the differences between AC and DC were is not obvious to the most of the respondents. For some of the respondents, these charging options were appraised equally. This equal assessment was highly negatively correlated with the acceptance of electric mobility in general. For instance, one respondent named the construct "crackbrained" to describe regular public charging stations. In his view, they are "the opposite of practical", and he reported that he does "not understand why they have not been sabotaged yet". Accordingly, all the other options of charging facilities were rated similar to regular public charging.

Another important factor is a lack of trust with regard to new technologies. Especially, missing experiences with high voltages lead to this distrust. One factor that likely contributes to this scepticism of charging is the fact that humans are unable to sense electricity without actually touching it. Electricity is typically associated with danger and life-threatening situations, and handling it is neither common nor routinized. In contrast, refuelling a car is common and routinized, despite the fact that gasoline is also potentially dangerous. Consequently, a lack of experience with charging leads to a reliance on publicly accessible information about charging and the familiar refuelling construct system.

After being asked about their daily mobility routines and actual their traffic behaviour, charging at origins and destinations seemed to be the most accepted option. Both charging options (regular charging in public and fast charging) were predominantly seen as an interruption of mobility that was perceived as a greater inconvenience than refuelling a car at a gas station. Thus, refuelling was perceived as being most different from fast charging. The average similarity for fast charging and regular refuelling was merely $54 \%$, which represents the lowest match between fast charging and the other options. This differentiation is based on various reasons. On the one hand, there are respondents that verbalize normative constructs such as "clean - dirty", and "modern - old fashioned". Environmental consciousness was important to some respondents. On the other hand, respondents perceived refuelling as a familiar and approved method that is used on a daily basis. Thus, trip interruptions are not recognized. In relation to other charging options, this option appears to require a comprehensive infrastructure that does not yet exist, prior to acceptance by the majority of the respondents.
Respondents saw concepts that include a plug-in charging station as very similar to one another. Whether or not respondents have previously noticed charging stations dominated their assessments, because most of the respondents do not yet have practical experiences with charging. Regular refuelling represents the main point of reference when assessing other options. Therefore, other elements are typically contrasted with this option. Battery exchange and inductive charging, which were both novel to most of the respondents, were mostly rated as acceptable alternatives to refuelling ICEVs. Although fast charging was associated with higher flexibility, when respondents started to reflect their own mobility patterns it became clear that this option was perceived as difficult to implement into daily routines. Fast charging may not always be the best option, unless it hits the benchmark and can take place within a time frame that is comparable to refuelling an ICEV.

\section{Conclusion}

A novel contribution of the present research is the first analysis of the perception of fast charging of BEVs compared to other charging and refuelling options. Using the Repertory Grid Technique developed by Kelly according to his Personal Construct Theory, we were able to elicit constructs of assessment of different charging and refuelling options and explore similarities and differences in the perception of those options. In the characterisation of current mobility routines, knowledge of refuelling processes dominated perceptions charging. For most of the respondents this background served as the benchmark for all the different charging options for BEVs and implies an apparent obstacle of electric mobility. In addition, public media influences the assessment and provides constructs making up for the lack of respective experiences. Range as a publicly distributed construct was initially the main factor in the acceptance of charging BEVs. It was connected to constructs such as "independency", "flexibility" and "availability". These construct poles represent a form of mobility that is shaped by experiences with ICEVs. The current state of charging technology does not satisfy the requirements of mobility, since it leads to the necessity of developing new routines.

However, for the majority of our sample, the integration of charging into daily routines was seen as an acceptable option of electric mobility for the majority. Charging processes during shopping, while at work, or participating in leisure activities were rated as attractive alternatives to refuelling ICEVs. For respondents, it was important that charging proceeds without being noticed. Charging BEVs at home generally provided the most appealing option for the respondents. Early adopters of BEVs are yet able to integrate the charging processes into their daily life and develop new routines of traffic behaviour. 
Respondents without driving experiences appeared to find it difficult to imagine having to change their routines, but did not exclude the possibility entirely.

In order to leverage electric mobility, it is crucial to gain an alternative understanding of mobility, which has to be governed by different ideological and guiding principles. Gas stations currently offer a comprehensive infrastructure for refuelling ICEVs. However, they are not accepted though as locations for charging BEVs with direct current. Accordingly, the concept of gas stations could become obsolete for charging BEVs. In addition, respondents were not able to imagine daily routines with a $30 \mathrm{~min}$ break at a gas station, or the fact of needing to relocate the car after it is fully charged. The duration of charging needs to be short enough to "disappear in the background" when charging at public stations. However, the possibility of integrating charging with other activities was seen as a highly accepted option of charging BEVs. Using charging periods for other activities was accepted at high rates because it fulfills the requirement of invisible charging. Thus, integration of charging into daily routines is the key to acceptance of electric mobility. Nevertheless, if charging at a gas station were possible within a duration comparable to the current process of refuelling, it would be possible to maintain the current mobility culture.

A complete understanding of mobility presupposes its reflection. In order to support the acceptance of new forms of mobility, it is critical to raise awareness of the traffic behaviours of all individuals. The present study provides insight into rarely verbalized routines, perceptions and assessments of charging, since the actual traffic behaviour is highly routinized for most of the people. Research about range anxiety has concluded to providing a comprehensive charging infrastructure as a key of acceptance. In our paper we demonstrate that this may not be necessary once respondents reflect their actual daily routines. Our results suggest that range anxiety can be overcome by other practices such as raising awareness of actual traffic behaviour rather than building a comprehensive charging infrastructure.

\footnotetext{
Acknowledgments The CCS project is part of the Berlin-Brandenburg International Showcase for Electromobility, which is funded by the federal government as well as by the federal states of Berlin and Brandenburg for 3 years as part of the federal government's Showcase initiative. CCS combines both charging stations (alternating current (AC) and direct current (DC)) for battery electric vehicles and tests them in highly visible places in Berlin.
}

Open AccessThis article is distributed under the terms of the Creative Commons Attribution 4.0 International License (http:// creativecommons.org/licenses/by/4.0/), which permits unrestricted use, distribution, and reproduction in any medium, provided you give appropriate credit to the original author(s) and the source, provide a link to the Creative Commons license, and indicate if changes were made.

\section{References}

1. Ahrend C (2009) Spotlights. Zukünfte in Mobilitätsroutinen. In Zukunftsforschung und Zukunftsgestaltung. Beiträge aus Wissenschaft und Praxis, R. Popp and E. Schüll, Editors. Berlin, Heidelberg. p. 307-312

2. Ahrend C et al (2013) Kleiner Begriffskanon der Mobilitätsforschung, in Discussion Paper, T.B. Integrierte Verkehrsplanung, Editor

3. Bakker J (2011) Contesting range anxiety: the role of electric vehicle charging infrastructure in the transportation transition. Eindhoven University of Technology

4. Bannister D, Fransella F (1986) Inquiring man: The psychology of personal constructs. 3 ed, London, Dover, N.H: Croom Helm. viii, 194

5. Bühler F et al (2014) Is EV experience related to EV acceptance? Results from a German field study. Transportation Research Part F: traffic psychology and behaviour. 25, Part A(0): p. 34-49

6. Chan CC, Chau KT (2001) Modern electric vehicle technology, vol 47. Oxford Press, Oxford

7. De Craemer K, Deconinck G (2012) Balancing trade-offs in coordinated PHEV charging with continuous market-based control. p. $1-8$

8. Dick M (2000) Die Anwendung narrativer Gridinterviews in der psychologischen Mobilitätsforschung. Forum: Qualitative Sozialforschung (1 (2))

9. Embacher J, Buttle F (1989) A repertory grid analysis of Austria's image as a summer vacation destination. J Travel Res 27(3):3-7

10. Franke T, Krems JF (2013) Understanding charging behaviour of electric vehicle users. Transport Res F: Traffic Psychol Behav 21: 75-89

11. Franke T, Krems JF (2013) What drives range preferences in electric vehicle users? Transp Policy 30:56-62

12. Franke $\mathrm{T}$ et al (2012) Experiencing range in an electric vehicle: understanding psychological barriers. Appl Psychol 61(3):368-391

13. Fransella F (2003) International handbook of personal construct psychology. Wiley, Chichester, p 529

14. Frolik J, Hines P (2012) Random access, electric vehicle charge management. p. 1-4

15. Fromm M (1995) Repertory Grid Methodik: Ein Lehrbuch. Deutscher Studien Verlag, Weinheim

16. Fromm M (2004) Introduction to the repertory Grid interview. Waxmann, Münster, p 189

17. Fromm M, Bacher A (2003) GridSuite 2.1.0: Software zur Erhebung, Bearbeitung und Auswertung von Repertory-GridInterviews. /04

18. Fromm M, Paschelke S (2010) GridPractice: Anleitung zur Durchführung und Auswertung von Grid-Interviews. 1 ed. Norderstedt: Books on Demand. $184 \mathrm{~S}$

19. Gharbaoui M et al (2012) An advanced smart management system for electric vehicle recharge. p. 1-8

20. Greaves S, Backman H, Ellison AB (2014) An empirical assessment of the feasibility of battery electric vehicles for day-to-day driving. Transp Res A Policy Pract 66:226-237

21. Guo $\mathrm{C}$ et al (2012) Planning method of charging infrastructure based on energy equivalent. p. 739-744

22. Halvgaard R et al (2012) Electric vehicle charge planning using Economic Model Predictive Control. p. 1-6

23. Harms S (2002) Besitzen oder Teilen. Vom Routinehandeln zur bewusst-rationalen Wahl zwischen Mobilitätsalternativen: Wann steigen Autobesitzende auf das Car Sharing um? Rügger Verlag, Zürich

24. Jankowicz D (2004) The easy guide to repertory grids. Chichester, West Sussex, England, Hoboken, NJ: J. Wiley. 1 online resource (xix, 308 
25. Kelly GA (1955) Clinical diagnosis and psychotherapy. 1 ed. The psychology of personal constructs. New York, NY: Norton. 5591218

26. Kelly GA (1963) A theory of personality. Norton, New York, p 190

27. Kelly GA (1986) Die Psychologie der persönlichen Konstrukte. Reihe innovative Psychotherapie und Humanwissenschaften. Paderborn: Junfermann. $191 \mathrm{~S}$

28. Lim MK, Mak H-Y, Rong Y (2015) Toward mass adoption of electric vehicles: impact of the range and resale anxieties. Manuf Serv Oper Manag 17(1):101-119

29. Lin Z, Greene DL (2010) Rethinking FCV/BEV vehicle range: a consumer value trade-off perspective. Medium: $X$

30. Machiels $N$ et al (2014) Design criteria for electric vehicle fast charge infrastructure based on flemish mobility behavior. IEEE Trans on Smart Grid 5(1):320-327

31. Marsden D, Littler D (2000) Repertory grid technique - An interpretive research framework. Eur J Mark 34(7):816-834

32. Meyer M, Freitag M (2009) In: Kühl S, Strodtholz P, Taffertshofer A (eds) Repertory Grid, in Handbuch Methoden der Organisationsforschung. VS Verlag für Sozialwissenschaften, Wiesbaden

33. Moura SJ et al (2010) Tradeoffs between battery energy capacity and stochastic optimal power management in plug-in hybrid electric vehicles. J Power Sources 195(9):2979-2988

34. Nilsson M (2011) Electric vehicles: an interview study investigating the phenomenon of range anxiety
35. Pearre NS et al (2011) Electric vehicles: how much range is required for a day's driving? Transp Res Part C: Emerg Technol 19(6):1171-1184

36. Pike S (2007) Repertory grid analysis in group settings to elicit salient destination image attributes. Curr Issues Tourism 10(4): 378-392

37. Riley S, P. J (1975) Of attitudes and lattitudes: a repertory grid study of seaside resorts. J Market Res Soc (17): p. 74-89

38. Rogers B, Ryals L (2007) Using repertory grid to access the underlying realities in key account relationships. Int J Market Res (49 (5)): p. 595-612

39. Scheer JW, Catina A (1993) Einführung in die Repertory GridTechnik: Grundlagen und Methoden. 1 ed. Bern: Hans Huber. $96 \mathrm{~S}$

40. Schroeder A, Traber T (2012) The economics of fast charging infrastructure for electric vehicles. Energy Policy 43:136-144

41. Simpson M, Markel T (2012) Plug-in electric vehicle fast charge station operational analysis with integrated renewables. In International Battery, Hybrid and Fuel Cell Electric Vehicle Symposium 26. California

42. Thieme DPN (2011) Repertory Grid Methodik, in Empirische Forschung und Soziale Arbeit. Springer. p. 281-291

43. Wilke G (2002) Neue Mobilitätsdienstleistungen und Alltagspraxis. Institut für Klima, Umwelt. Wuppertal Papers

44. Wu C et al (2010) A method for electric vehicle charging infrastructure planning [J]. Autom Electr Power Syst 24:007

45. Yilmaz M, Krein PT (2012) Review of charging power levels and infrastructure for plug-in electric and hybrid vehicles. p. 1-8 